\title{
Permanent tolerance induced by oral immunotherapy; is it a complete symptom-free condition? a prospective cohort study
}

saba $\operatorname{arshi}^{1}$, Fatemeh Alizadeh ${ }^{1}$, mohammad nabavi ${ }^{1}$, mohammad hasan bemanian ${ }^{1}$, sima shokri $^{1}$, Farhad Seif ${ }^{2}$, Majid Khoshmirsafa ${ }^{1}$, and morteza fallahpour ${ }^{1}$

${ }^{1}$ Iran University of Medical Sciences

${ }^{2}$ Academic Center for Education Culture and Research

June 3,2020

To the Editor

At present, strict food avoidance is the only standard treatment for food anaphylaxis. Incidental exposure, cross-contamination, incomplete adherence, nutrient and psychological deprivations in parallel to significant quality of life impairment of the patient and his/her family led to many attempts to find alternative therapies, including oral immunotherapy (OIT) that showed promising clinical implications [1]. During OIT, gradually increasing doses from very small amounts are given to the patient at specified intervals until a predetermined final dose is reached (build-up phase). If the patient reaches this final dose, he/she has to take this maintenance continuously in a regular daily schedule (maintenance phase). An allergic reaction as mild as local pruritus of the lips or as severe as anaphylaxis is the main limitation of both phases. The primary consequence during OIT is the reduction of anaphylaxis risk in accidental exposures and the second consequence is the achievement of permanent tolerance (PT)[2].

During desensitization, unresponsiveness is accessible as long as the patient adheres to the instructions, while during PT, unresponsiveness is independent of adherence to the schedule. Natural tolerance (NT) is seen in infants with food allergy and develops with increasing the age but inducible permanent tolerance (IPT) is seen in some patients doing OIT [2,3]. Currently, not only the immunologic mechanisms or prognostic factors in success or failure of OIT and the achievement of PT are not fully understood but also it is not clear that inducible permanent tolerance really works like natural tolerance? How can we say to a patient with food anaphylaxis that he/she is definitely cured? Therefore, we designed this study to assess the possible reactions of patients with anaphylaxis after the achievement of PT.

This prospective cohort study was conducted on patients with cow's milk anaphylaxis who underwent OIT in the Allergy and Clinical Immunology Department of Rasoul-e-Akram Hospital, Tehran, Iran [4]. All of the participants or their parents signed written informed consent form and the Ethics Committee of Iran University of Medical Sciences approved this study (IR.IUMS.FMD.REC.1397.333). Twenty-one patients who met the inclusion criteria, including cow's milk anaphylaxis, successful OIT with more than 48 months of the maintenance phase, complete adherence to maintenance phase protocol were allocated to this study. After 4 weeks of complete dairy avoidance, they underwent a standard oral food challenge (OFC) [5]. Eight out of 21 individuals who could pass the OFC were diagnosed as PT and approved for this study.

In the first week, they were asked to take a double and triple amount of the maintenance dose in the hospital. All of them consumed this amount of milk without any reaction and then they were asked to take any amount of cow's milk or dairy products regardless of timing similar to non-allergic individuals. They were given a 24-hour contact number to report any symptoms immediately, and we followed them weekly by phone for 6 months. Any kind of reactions, the severity of symptoms, type of relieving drug, the interval of usage, 
amount of milk consumption, and the existence of aggravating factors such as exercise, fever, and infection was monitored. All of them showed a significant decrease in specific IgE and IgG4 to cow's milk before and after the OIT. Seven of eight participants showed some reactions after cow's milk consumption. Reactions were mild and only oral antihistamines were used for treating the reactions. All of the symptoms were appeared along with exacerbating factors. Cow's milk consumption without aggravating factors was safe independent of the amount and interval of the consumption. Exercise in the first hour after drinking milk was the most common trigger in our participants. Data are shown in table 1.

We conducted a prospective cohort study in cow's milk anaphylactic patients with successful OIT. Out of 21 patients, only 8 cases passed the OFC after 4 weeks of cessation of dairy consumption and were diagnosed as PT state [2]. There are two different definitions in OIT. Desensitization refers to a temporary state of unresponsiveness of the adaptive immune system to a specific antigen, which is dependent on continuous use of the predetermined amount of that food, while permanent tolerance is defined as persistent unresponsiveness of the adaptive immune system to that antigen, irrespective of amount and consumption continuity [2, 3]. It is estimated that about 30 to $90 \%$ of individual who undergo OIT are able to achieve desensitization state $[2,6]$ but the rate of PT is unknown and is reported between 28 to $36 \%$ in limited trials [3, 6], it is suggested longer maintenance phase and higher amount of daily use may have some role in PT development [2].

In this study, 8 of 21 (38\%) patients developed PT. The success rate of PT induction was not our aim. We wanted to provide more information about possible reactions related to milk ingestion after PT achievement. The main question was: Can we really give assurance to patients with anaphylaxis that they are completely safe in the exposure to the culprit food, regardless of the dose and continuity of consumption? To the best of our knowledge, it is the first time to follow these individuals after PT development; however, Nowak-Wegrzyn $\mathrm{A}$ and Deborah $\mathrm{M}[2,7]$ also asked this question without a clear response. Allergic reactions are the main side effects during OIT in both escalation and maintenance phases. It is important to consider that in the maintenance phase of desensitization, patients may show severe reactions to previously tolerated doses in association with exercise, viral infection, dosing on an empty stomach, menses, and asthma exacerbation. It is hypothesized that these factors may increase intestinal permeability, thereby leading to loss of protection to the previously tolerated dose, even when the maintenance dose has been achieved regularly [2]. Interestingly, our study showed these factors could affect the unresponsiveness state even when PT has developed; however, none of our patients showed severe reactions. The present study showed the dose and continuous consumption of food allergen were not involved in the reaction after PT development but aggravating factors are still important.

Signature

1-Saba Arshi, MD, associate professor of allergy \& clinical immunology, Allergy department, Rasoul e Akram hospital, Iran University of Medical Sciences, Tehran, Iran,

2- Fatemeh Alizadeh, MD, pediatrician, pediatric department, Rasoul e Akram hospital, Iran University of Medical Sciences, Tehran, Iran,

3-Mohammad Nabavi, MD, associate professor of allergy \& clinical immunology, Allergy department, Rasoul e Akram hospital, Iran University of Medical Sciences, Tehran, Iran,

4- Mohammad Hasan Bemanian, MD, associate professor of allergy \& clinical immunology, Allergy department, Rasoul e Akram hospital, Iran University of Medical Sciences, Tehran, Iran,

5-Sima Shokri, MD, assistant professor of allergy \& clinical immunology, Allergy department, Rasoul e Akram hospital, Iran University of Medical Sciences, Tehran, Iran,

6-Majid KhoshMirsafa, Phd, assistant professor of immunology, Immunolgy department, medical school, Iran University of Medical Sciences, Tehran, Iran

7-Farhad Seif, Phd, assistant professor of immunology, department of allergy \& immunology, Academic Center for Education, Culture, and Research, Tehran, Iran 
8- Morteza Fallahpour, MD, assistant professor of allergy \& clinical immunology, Allergy department, Rasoul e Akram hospital, Iran University of Medical Sciences, Tehran, Iran,

\section{Reference}

[1] P. Capucilli, K. Kennedy, J. Lee, R. W. Grundmeier, and J. M. Spergel, "Accidental versus new food allergy reactions in a pediatric emergency department," The Journal of Allergy and Clinical Immunology: In Practice, vol. 7, pp. 1662-1664, 2019.

[2] A. Nowak-Wegrzyn and A. Fiocchi, "Is oral immunotherapy the cure for food allergies?," Current opinion in allergy and clinical immunology, vol. 10, pp. 214-219, 2010.

[3] T. P. Moran and A. W. Burks, "Is clinical tolerance possible after allergen immunotherapy?," Current allergy and asthma reports, vol. 15, p. 23, 2015.

[4] D. Babaie, M. Nabavi, S. Arshi, M. Mesdaghi, Z. Chavoshzadeh, M. H. Bemanian, et al. , "Cow's milk desensitization in anaphylactic patients: a new personalized-dose method," Iranian Journal of Allergy, Asthma and Immunology, vol. 16, pp. 45-52, 2017.

[5] M. Plaut, R. T. Sawyer, and M. J. Fenton, "Summary of the 2008 National Institute of allergy and infectious diseases-US food and drug administration workshop on food allergy clinical trial design," Journal of Allergy and Clinical Immunology, vol. 124, pp. 671-678. e1, 2009.

[6] M. Tang and D. Martino, "Oral immunotherapy and tolerance induction in childhood," Pediatric Allergy and Immunology, vol. 24, pp. 512-520, 2013.

[7] D. M. H. Freeland, H. Fan-Minogue, J. M. Spergel, T. A. Chatila, and K. C. Nadeau, "Advances in food allergy oral immunotherapy: toward tolerance," Current opinion in immunology, vol. 42, pp. 119-123, 2016.

Table1. Clinical and laboratory data

\begin{tabular}{|c|c|c|c|c|c|c|c|c|c|c|c|}
\hline Patient & Gender & $\begin{array}{l}\text { Anap } \\
\text { his- } \\
\text { tory }\end{array}$ & $\begin{array}{l}\text { Mainten } \\
\text { laßisra- } \\
\text { tion } \\
\text { (month) }\end{array}$ & $\begin{array}{l}\text { ance } \\
\text { OIT }\end{array}$ & OIT & OIT & OIT & $\begin{array}{l}\text { Reactio } \\
\text { with- } \\
\text { out } \\
\text { aggra- } \\
\text { vating } \\
\text { factor }\end{array}$ & $\begin{array}{l}\text { Reaction } \\
\text { with } \\
\text { aggra- } \\
\text { vating } \\
\text { factor }\end{array}$ & $\begin{array}{l}\text { n } \\
\text { Type } \\
\text { of re- } \\
\text { action }\end{array}$ & $\begin{array}{l}\text { Relieving } \\
\text { drug } \\
\text { for } \\
\text { treat- } \\
\text { ment }\end{array}$ \\
\hline & & & & $\begin{array}{l}\text { SIgE } \\
\text { (kUA/I }\end{array}$ & $\begin{array}{l}\text { SIgE } \\
(\mathbf{k U A} /\end{array}$ & $\begin{array}{c}\text { sIgG } \\
(\mathrm{mg} / \mathrm{mI}\end{array}$ & \multicolumn{5}{|c|}{$\begin{array}{l}\text { sIgG } \\
(\mathrm{mg} / \mathrm{mL})\end{array}$} \\
\hline & $\begin{array}{l}\text { Age } \\
\text { (year) }\end{array}$ & & & Before & After & Before & \multicolumn{5}{|l|}{ After } \\
\hline 1 & $\begin{array}{l}\text { Male } \\
12\end{array}$ & Yes & 50 & 35.96 & 19 & 9.36 & 15.25 & No & Yes & $\mathbf{L U}$ & $\mathbf{H}$ \\
\hline 2 & $\begin{array}{l}\text { Male } \\
11\end{array}$ & Yes & 48 & 48 & 0.63 & 17 & 29 & No & Yes & $\mathbf{L U}$ & $\mathbf{H}$ \\
\hline 3 & $\begin{array}{l}\text { Male } \\
15\end{array}$ & Yes & 56 & 12.86 & 1.9 & 10.71 & 16.52 & No & Yes & $\mathbf{G U}$ & $\mathbf{H}$ \\
\hline 4 & Female & Yes & 64 & 9.49 & 4.06 & 4.85 & 48 & No & Yes & $\begin{array}{l}\text { Rh, } \\
\mathbf{U}\end{array}$ & $\mathbf{H}$ \\
\hline 5 & $\begin{array}{l}\mathbf{9} \\
\text { Male }\end{array}$ & Yes & 48 & 28 & 2.35 & 65 & $>100$ & No & Yes & $\begin{array}{l}\mathbf{N} \\
\mathbf{L U}\end{array}$ & $\mathbf{H}$ \\
\hline 6 & $\begin{array}{l}23 \\
\text { Male }\end{array}$ & Yes & 52 & 23.5 & 2.44 & 43 & 87.66 & No & No & - & - \\
\hline
\end{tabular}




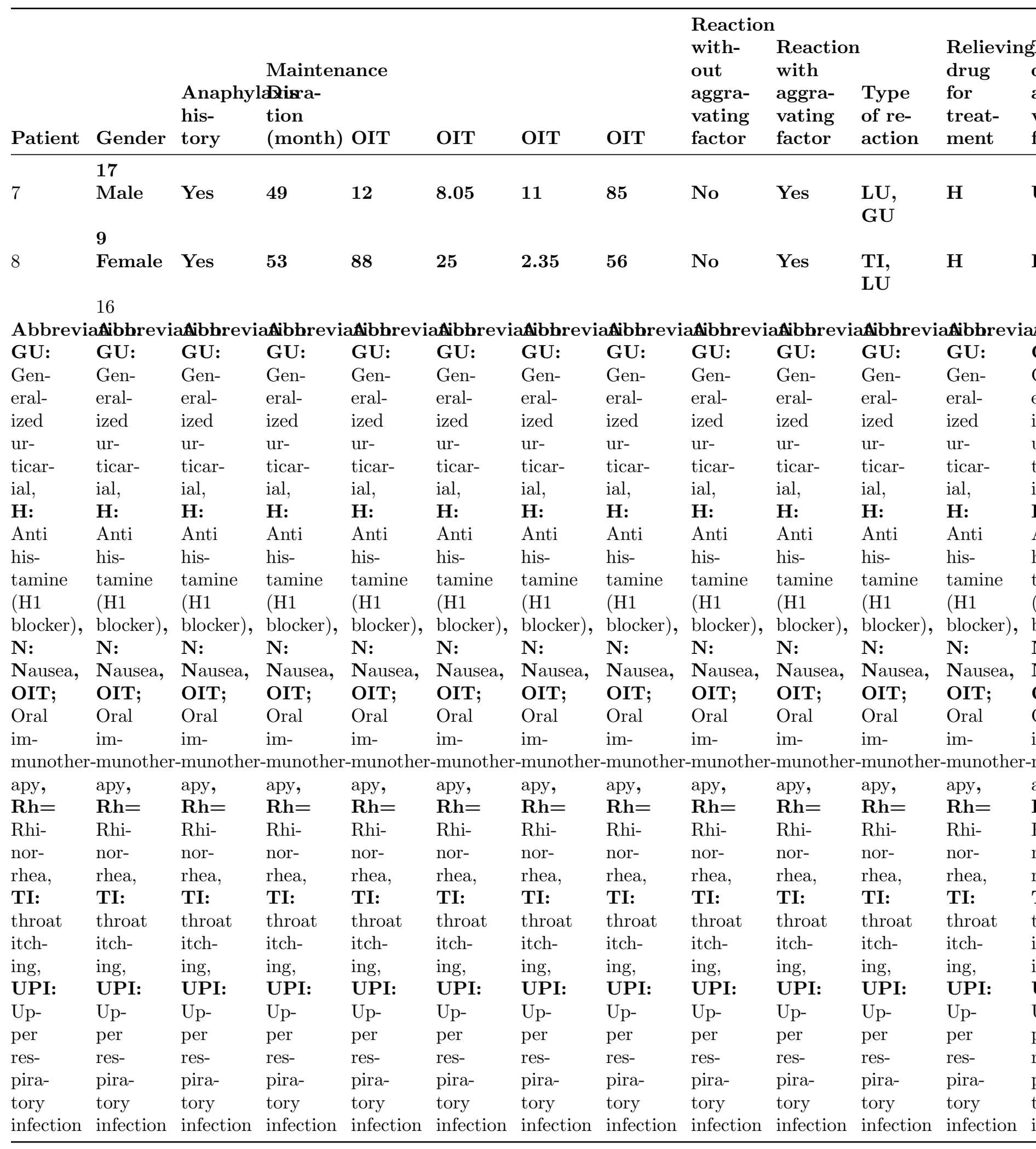

